\title{
(2) OPEN ACCESS \\ Medical informed choice: understanding the element of time to meet the standard of care for valid informed consent
}

\author{
Zachary R Paterick, ${ }^{1}$ Timothy Edward Paterick (10, ${ }^{2}$ Barb Block Paterick ${ }^{3}$
}

\begin{abstract}
${ }^{1}$ Law, University of Michigan, Ann Arbor, Michigan, USA ${ }^{2}$ Cardiology, Aurora, Hobart, Wisconsin, USA

${ }^{3}$ Law, University Of Wisconsin Colleges, Madison,

Wisconsin, USA
\end{abstract}

Correspondence to Dr Timothy Edward Paterick, Cardiology, Aurora, Hobart, WI 54155, USA:

tpaterick@gmail.com

Received 1 November 2019 Revised 24 November 2019 Accepted 9 December 2019

Check for updates

(C) Author(s) (or their employer(s)) 2020. No commercial re-use. See rights and permissions. Published by BMJ.

To cite: Paterick ZR, Paterick TE, Paterick BB. Postgrad Med J 2020:96:708-710.

\begin{abstract}
Medical informed choice is essential for a physician meeting their fiduciary duty when proposing medical and surgical actions, and necessary for a patient to consent or cull the outlined therapeutic approaches. Informed choice, as part of a shared decision-making model, allows widespread give-and-take of ideas between the patient and physician. This sharing of ideas results in

a partnership for decision-making and a responsibility for medical and surgical outcomes.

Informed choice is indispensible to the patient education process that meets the desired outcome of any covenant -an offer of and acceptance of the proposed treatment. The covenant anchors a true patient-physician partnership with parity and equality in decision-making and medical/surgical outcomes.

Medical informed choice flows from ethical and legal principles necessary to meet the acknowledged standard of care. This is codified by statute and fortified in general common law. This espouses a fiduciary relationship where the patient and physician understand and accede to the degree of autonomy the patient requests.

The growth of an equal patient-physician relationship requires time. There is no alternative to the time variable when developing a physician-patient relationship. Despite physicians being under pressures to perform more clinical and administrative duties in less time in the corporate model of medicine, time remains the most critical variable when considering informed choice and shared decision-making. Videos, pamphlets and alternate healthcare providers cannot and should not substitute for physician time.
\end{abstract}

\section{INTRODUCTION}

In today's medical market-place physicians are working at a feverish pace to meet the demands of the business model decreed by their employer. That business model has physicians seeing more patients in less time. The operative word is 'time' because quality work requires time and meeting the medical professional standard of care requires time.

The medical standard of care is the ethical and legal duty of a professional to exercise the level of care, diligence and skill prescribed in the 'code of practice' of her profession, or as other professionals in the same discipline would in the same or similar circumstances. ${ }^{1}$ This is the standard physicians face as they practise in a fast-paced medical market-place where reimbursements are shrinking and increased patient volumes is the prevailing mechanism to increase revenues. That creates a dilemma for physicians as faster pace means less time, and less time means less deliberation and diligence in taking a medical history, performing a physical examination, developing a differential diagnosis and educating patients about the elements of medical choice and then making an informed, knowledgeable and voluntary decision about the healthcare they want or don't want. That shared, informed decisionmaking process is time-dependent.

Time is the dependent variable in the informed choice function of meeting the standard of care of informed consent. The new healthcare business equations are creating a shrinking time variable. This disconnect between patient care and business models of medicine puts physicians at risk for failing to meet the threshold for the informed consent standard of care. This failure may place physicians at risk for allegations of negligence. The time disconnect weighs heavy on physicians' minds as they constantly face the potential of alleged liability. Shrinking time with patients can never lead to increased quality or a trusting physician-patient relationship.

Physicians have a moral, legal and ethical responsibility to understand medical informed choice. This responsibility emanates from the fiduciary duty physicians owe patients. Furthermore, true informed choice results in a meeting of the elements of the standard of care and limits any potential for alleged negligence. $^{2}$

In this manuscript we will address the patient and physician criteria for medical choice to be valid, the exceptions to obtain medical informed choice, the ethical and legal foundations to medical informed choice, the different standards that are adequate to meet the standard of care and the fact that no single paradigm fits all patient situations.

\section{MEDICAL INFORMED CHOICE: PATIENT CRITERIA FOR VALID INFORMED CHOICE}

What considerations define if patients are capable of participating in the informed choice/shared decisionmaking process? The determination is dependent on deciding if the patient is mentally capable and has decision-making capability. Capacity is a person's ability to make an informed decision. Succinctly stated the patient must be able to comprehend the information presented and the associated potential benefits, risks and alternative choices to their medical care.

Every part of a patient decision must be intentional. Family members, other interested parties or 
healthcare professionals should not affect decisions. It is imperative that medications or life stressors should not compromise patients involved in informed choice/shared decision-making. A patient with intact cognitive capacity and intact decisionmaking capacity may reverse a medical/surgical decision at any point in time. The competent patient may reject any proposed treatment despite the consequences of that decision. ${ }^{3}$

\section{PHYSICIAN CRITERIA FOR INFORMED CHOICE TO BE VALID}

What subjects must a physician share with a patient to meet the threshold for valid informed choice/shared decision-making? Physicians must divulge to patients the diagnosis, the nature and purpose of the proposed treatment or procedure, reasonable available alternative approaches, relevant risks, benefits and uncertainties of each alternative, and the risks and benefits of not choosing a treatment or procedure. ${ }^{2}$ Additionally, physicians should take the time to conclude that the patient understands the diagnosis, treatment choices, and the risks and benefits of treatment versus no treatment.

\section{THE EXCEPTIONS TO OBTAINING INFORMED CHOICE}

Exceptions to medical informed choice occur when physicians are confronted with medical emergencies that would result in permanent injury or death without immediate intervention. In these unique circumstances even though the patient preferences/ desires are unknown, informed consent is presumed. ${ }^{4}$

Additional exceptions to informed choice include a patient foregoing a right of informed choice and therapeutic privilege. By signing a waiver a patient freely and wilfully relinquishes a legal right. Patients may elect to sign a medical waiver when considering medical informed choice/shared decision-making. The patient may choose a surrogate decision-maker or adopt the physician as the decision-maker. Caution should be abundant when using a waiver for informed choice. Legally, waivers can be a slippery slope and it is in the best interest of physicians to involve the risk management/legal team to develop an exhaustive legal covenant. ${ }^{5}$

The therapeutic privilege is a doctrine allowing the physician to withhold information if the disclosure of the knowledge would actually harm the patient. The therapeutic privilege should be used on rare occasions since it is dicey ethically and legally. State precedent would govern the interpretation of the therapeutic privilege and court analysis is variable state to state. In these circumstances it is imperative for the physician to document in detail the rationale for invoking the therapeutic privilege and should have the ethics and risk management teams involved. ${ }^{5}$

\section{ETHICS AND INFORMED CHOICE}

Beneficence and non-maleficence

Beneficence (doing good) and non-maleficence (do not harm) underlie the physician's moral imperative. This moral imperative infers there are times/circumstances when partial disclosure or no disclosures are concordant with meeting the standard of care and fiduciary duties. This flows from the fact that some patients are emotionally incapable of handling discussions that entail life and death issues/consequences when they are in a regressed state of mind. This permits physicians the opportunity to modify the medical information they deliver to patients in an empathic manner that meets the moral imperative of beneficence and nonmaleficence. The ultimate goal of informed choice should be respect for a patient's autonomy combined with tactful application of beneficence and non-maleficence. ${ }^{6}$ This requires ongoing conversations over time and a trusting partnership.

\section{THE LEGAL FOUNDATION FOR INFORMED CHOICE}

The legal basis for mandating informed choice dates back to the 1700s. In Slater $v$ Baker and Stapleton, ${ }^{7}$ the court established that physicians should obtain consent from patients before surgery and could be held legally liable if they proceeded without informed consent.

In Schloendorff $v$ Society of New York Hospital ${ }^{8}$ (1914) a physician removed a tumour from a patient who had only consented to an examination and had refused an operation. Justice Cardozo wrote: 'Every human being of adult years and sound mind has a right to determine what shall be done with his own body; and a surgeon who performs an operation without his patient's consent commits an assault, for which he is liable in damages'. Schloendorff established the necessity of voluntary agreement for each specific proposed procedure.

The phrase 'informed consent' was born in the California Court of Appeals case Salgo $v$ Leland Stanford Jr. University Board of Trustees. ${ }^{9}$ The court held that a physician could be held liable for failing to provide facts about a proposed treatment that are necessary for a patient to make an informed decision. Additionally, the decision stated that physicians must exercise discretion when deciding what risks to disclose in order to protect a patient's well-being. This decision failed to delineate any clear limits on what must be disclosed. The California Supreme Court articulated this uncertainty: 'One cannot know with certainty which medical consent is valid until a lawsuit is filed and resolved'. ${ }^{10}$ There does not appear to be a standard of disclosure to which physicians can adhere to avoid liability with certainty. $^{2}$

\section{WHAT DOES THE COURT REVIEW WHEN PRESENTED WITH AN INFORMED CONSENT CASE?}

When a case advances to court, appropriate documentation of the informed choice process can be used as a defence that the physician properly informed a patient about a treatment or procedure. That documentation should be obtained in the medical record. Physicians should document the details of the discussion and the time devoted to educating the patient and answering the patient's questions.

Relying on informed consent forms may be helpful to satisfy legal requirements and make documentation more efficient, but they are not an acceptable replacement for time with the patient. The consent forms used to replace physician time negatively impact the physician-patient relationship. The use of informed consent forms have evolved into a legalistic process attempting to limit liability rather than facilitating comprehension and understanding of the treatment or proposed procedure. There is a feeling that the focus of physicians is on risk communication, and not on informed medical decision-making.

Sensibly if more time were spent educating and building a trusting partnership with the patient there would be less need to have consent forms and a lower likelihood of ending up in court facing an allegation of negligent informed consent. Ultimately on review of the medical record the court evaluates the time dedicated to information sharing and shared decision-making between the physician and the patient to determine if a physician met the standard of care for informed consent.

\section{DEFINING THE STANDARDS OF DISCLOSURE}

Two dominant approaches, the 'professional' standard and the 'materiality' standard, define the standard of disclosure of information by which a physician's duty to the patient is measured. ${ }^{11}$ 
The professional standard requires the physician to disclose information that other physicians possessing the same skills and practising in the same or a similar community disclose in a similar situation. ${ }^{212}$ The second approach by courts is the materiality or 'prudent patient' approach, allowing the jury to decide whether other information would have been considered important by a reasonable patient in making a decision and therefore requiring disclosure. $^{2} 13$

The courts recognise situations when a physician's nondisclosure will be excused, including cases of the patient's mental incompetence, medical emergencies and the therapeutic privilege exception. ${ }^{214}$ If a patient is incompetent to make a reasoned decision, then disclosure to the patient might not be required. ${ }^{2} 15$ The physician can also withhold information under the therapeutic privilege if disclosure would interfere with treatment or would adversely affect the condition or recovery of the patient. ${ }^{2} 16$ The emergency exception to disclosure applies in situations where attempting to secure consent would delay necessary and proper treatment. ${ }^{2}{ }^{17}$ Last, physicians need not disclose risks of which the patient is already aware, or risks that are commonly known. ${ }^{2}$ 18 Individual state law and court decisions determine which approaches and exceptions apply in an individual physician's practice.

In order to facilitate true informed consent some states have initiated shared decision-making legislation. Shared decisionmaking requires intense education of the patients. Pamphlets, videos and a vast array of telecommunication infomercials are often provided to patients, allowing them to more fully understand the proposed treatment or procedure and then incorporate their own values and preferences into the decision-making process. Providing additional written material, audiovisual, multimedia and test and feedback techniques, in addition to adequate time for education and shared decision-making all improve patient comprehension, especially regarding risks and general knowledge about the procedure.

\section{CONCLUSION}

There is no single prototype that meets the elements of the standard of care for informed consent that applies to all patients. Medical informed consent is essential to a true patient-physician relationship. Patients need to participate in the informed consent process to understand the risk-benefit relationship for the proposed treatment strategy; this understanding is essential because patients are often psychologically regressed secondary to the realisation that they are confronting a life-preserving procedure that cares significant risk.

Physicians need to participate in the informed consent process to provide patients with the best treatment available by sharing decision-making and limiting any potential for liability. Medical ethics, common law and, in many states, codified statutory law mandate the informed consent process. Physicians would be prudent to be knowledgeable in these areas of medical ethics, common law and statutory law.

Physicians would be judicious also to understand that the consent process is vital to the physician-patient relationship and that no single archetype can define the ethical, medical and legal approach a physician should undertake to achieve informed consent. The process should be individualised within the boundaries of the patient's desires for autonomy, thus reflecting true patient autonomy.

The overarching principle is meeting the elements of true informed choice/consent and informed consent requires time. Despite the evolving business model of medicine, physicians must demand the time to educate, counsel and share decisions with patients with an abundance of time. The constellation of abundant time, true partnership and sharing in the decisions is the panacea to preventing allegations of negligence.

Time cannot and must not be shorted as adjuncts such as pamphlets and videos are helpful, but cannot replace a physician taking time with a patient. All true relationships are time-dependent. Meaningful shared decisions require time and that time will result in better clinical decisions/outcomes and less potential for liability.

Contributors ZRP, TEP and BPP researched the literature and case law, and contributed to writing the manuscript, edited the manuscript and reviewed the final form.

Funding The authors have not declared a specific grant for this research from any funding agency in the public, commercial or not-for-profit sectors.

Competing interests None declared.

Patient consent for publication Not required.

Provenance and peer review Not commissioned; externally peer reviewed.

Open access This is an open access article distributed in accordance with the Creative Commons Attribution Non Commercial (CC BY-NC 4.0) license, which permits others to distribute, remix, adapt, build upon this work non-commercially, and license their derivative works on different terms, provided the original work is properly cited, appropriate credit is given, any changes made indicated, and the use is noncommercial. See: http://creativecommons.org/licenses/by-nc/4.0/.

\section{ORCID iD}

Timothy Edward Paterick http://orcid.org/0000-0002-7054-5976

\section{REFERENCES}

Professional standard of care. Available: http://www.businessdictionary.com/definition/ professional-standard-of-care.html

2 Paterick TJ, Carson GV, Allen MC, et al. Medical informed consent: general considerations for physicians. Mayo Clin Proc 2008;83:313-9.

3 American Medical Association. Informed consent.. Available: http:/www.ama.assn.org/ ama/pub/physician-resources/legal-topics/patient-[physician relationship/informedconsent.shtml

4 Arard A, Herlitz J, Hermeren G. Obtaining informed consent from patients in the early phase of acute myocardial infarction: physician experiences and attitudes (letter). Heart 2004:90:208-10.

5 Klove CA, DiBoise SJ, Pang B, et al. Informed consent: ethical and legal aspects. ThoraC Surg Clin 2005;15:213-9.

6 Steinberg A. Disclosure of information and informed consent: ethical and practical considerations. J Child Neurol 2009:24:1568-71.

7 Slater vs. baker and Stapleton Eng Rep 1767.

8 Schloendorff V. Society of N.Y. Hosp., 211 N.Y;125:129-30.

9 Salgo V Leland Stanford Jr. university board of Trusteees. Pacific Reporter, $2 d$ Series 1957;317:170-82.

10 Moore V Regents of the University of California, 51 CAL 3D D20 165 793. P 2D 479 291 CAL Rptr. note 411990.

11 Madare V Oschner Foundation Hospital, 505 so 2D 146 (La CT APP) 1987.

12 Canterbury V Spence, 446 F2d 772 (CadC) 1972

13 Cowman V Hornaday, 329, NW 2D 422 (lowa) 1983.

14 Meisel A. The "exceptions" to the informed consent doctrine: striking a balance between competing values in medical decision-making. Wis L Rev 1979:1979:413-88

15 Banks v Wittenberg, 266 NW 2d 78882 Mich App 274 (Mich App) 1978.

16 Carnerie F. Crisis and informed consent: analysis of a law-medicine malocclusion. Am J Law Med 1987;12:55-97.

17 Shafford V Louisiana state University, 448 so 2D 852 (La CT APP) 1984

18 Kissinger v Lofgren, 836 F 2d 678 (CA 1) [Mass] 1987 